\title{
Energy Storage Power Conversion System in the Micro-grid
}

\author{
Zhou Jinghua $^{1, a}$, Yang Zheng ${ }^{2, b}$, Zhang Xiaowei ${ }^{3, c}$ \\ ${ }^{1}$ Department of Electrical Engineering and Automation, North China University of \\ Technology,Beijing, 100041, China \\ ${ }^{2}$ Department of Electrical Engineering and Automation, North China University of \\ Technology,Beijing, 100041, China \\ ${ }^{3}$ Department of Electrical Engineering and Automation, North China University of \\ Technology,Beijing, 100041, China \\ aemail: zjh@ncut.edu.cn, bemail: yz1223081@163.com, ${ }^{\mathrm{c} e m a i l: ~ z x w @ n c u t . e d u . c n, ~}$
}

Keywords: Power Conversion System; Topologies; Control Strategy

\begin{abstract}
With the development of new energy sources such as wind power and solar power generation technology, distributed generation and micro-grid technology attract increasingly great attention. However, the renewable energy resources are intermittent in nature under the influence of meteorological fluctuations, and produce fluctuating active power. An energy storage system is indispensable for compensation of the active-power fluctuation, it can mitigate the disturbance and maintain the stability of voltage and frequency. Power conversion system(PCS), as an interface between storage system and public grid, plays an great role in achieving the power transfer between storage system and public grid. This paper summarize the current topologies and the control strategies commonly used in engineering under different working situations and requirements, and analyze their differences and characters, which will helps in choosing the PCS structures and control strategies.
\end{abstract}

\section{Introduction}

With the rapid development of global economy, the global electricity consumption surges which gives rise to the serious power supply shortage. Renewable energy sources such as wind turbine generators and photovoltaics provides a new way to resolve the problem. However, the distributed power such as photovoltaic power and wind power are intermittent and produce fluctuating active power. Interconnecting these intermittent sources to the utility grid at a large scale may affect the voltage and frequency control of the grid, and may lead to severe power quality issues[1]. Therefor , Energy storage system is very important for the micro-grid, it can store the excess power from the grid when the power supply is greater than the power consumption. On the other hand, it releases the shortage of power to the grid when the generation system produces a smaller power. The energy storage system brings a significant enhancement in power quality, stability and reliability to the grid. Therefor, the energy storage system is more and more widely used in distributed generation system and micro grid.

Energy storage system consist of two parts, storage facility and PCS. PCS, the interface between storage facility and micro grid(utility grid), operates the function of transferring and swapping energy between the storage system and the micro-grid bidirectionally. The structure and control strategy are significant for the stability, efficiency and performance of the PCS. This paper summarizes the commonly used topology structures, and analyzes their differences and characters. Then the control strategy is presented and summarized.

\section{Topologies and Control Strategies of PCS}

The storage facility in this paper is referred to storage battery units. PCS is a power electronic converter in nature used to regulate the power transfer between the storage facility and micro-grid. Figure 1 show the structure of the whole energy storage system. 


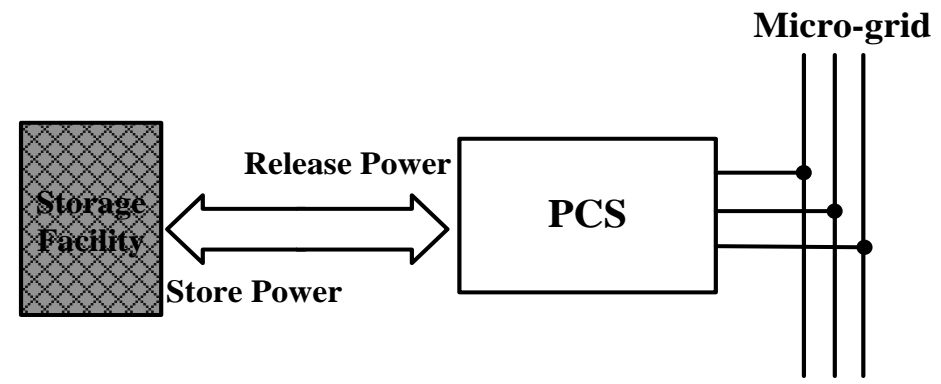

Fig.1 Structure of energy storage power conversion system

PCS has many topological structures, the commonly used structures such as single-stage PCS, two-stage PCS and cascaded PCS will be presented.

\section{A. Single-stage PCS}

Figure 2 shows the single-stage PCS topology. From the figure we can conclude that the PCS is essentially a bidirectional dc-ac converter. This converter can not only absorb superfluous energy from the grid and store the power in battery units, but also release energy stored in the battery banks to the grid and convert the dc voltage to ac voltage connected to the grid in order to keep the balance of the grid. Moreover, a filter could be installed in the output side of the battery unit to filter out the harmonics and mitigate the ripple in the currents injected into the grid.

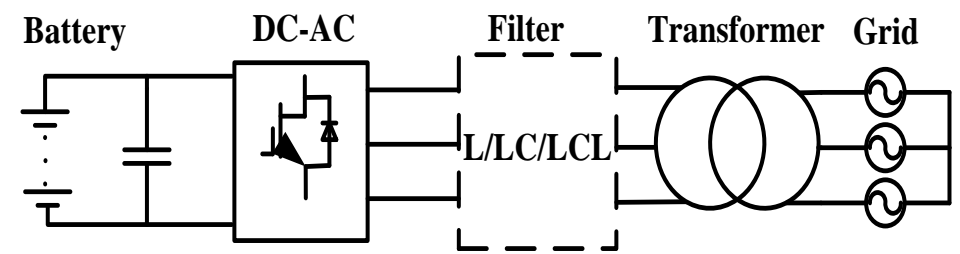

Fig.2 Topology of single-stage power conversion system

The prominent advantages of single stage PCS are the simple circuit structure, relatively simple control method, and less switch quantity which means less losses. However, the disadvantage is also obvious:the operation dc voltage of the battery units is limited; lack of flexibility of system capacity configuration and current-leveling ability of the battery units is poor, which effectively affect the battery lifetime.

For the single-stage PCS, there two aims for the control strategy. One is ensuring the balance of the active power in the grid, the other one is maintaining the voltage and frequency stability of the grid when unpredictable events occur and supporting the critical load connected to the grid. Currently, the commonly used control strategies include PQ control, V/f control and constant current control[2].

In on-grid mode, both the fluctuation in renewable sources generation power and the load will affect the voltage stability of the grid. The PQ control strategy could absorb or release proper power to keep the balance of the active power according to the requirement of the grid. Constant current control is designed to achieve unity power factor operation to satisfy the requirement for the current quality. Figure 3 shows the PQ control structure diagram, which employs the power outer loop and current inner loop for the purpose of maintaining the stability of the grid power and current connected to the grid in accordance with the command power signal.

In off-grid mode, in order to support the local load and maintain the continuous operation, a double-loop V/f control structure is adopted in this paper including a voltage outer loop and a current loop. Figure 4 shows the V/f control diagram. In the diagram, $u_{\text {dref }}$ and $u_{\text {qref }}$ are calculated from the droop character. Instantaneous active power $\mathrm{P}$ and reactive power $\mathrm{Q}$ can be calculated by sampled voltage and current of the converter output, thus $u$ and $f$ could be achieved by droop character equation. $u$ and $f$ compose the three-phase balanced instantaneous reference voltage $u_{\text {ref }}$. Finally, $u_{\text {dref }}$ and $u_{\text {qref }}$ can be achieved by applying the dq transformation. the droop characteristic equation can be expressed as 


$$
\left\{\begin{array}{c}
f-f_{0}=k_{p}\left(P-P_{i}\right) \\
U-U_{0}=k_{q}\left(Q-Q_{i}\right) .
\end{array}\right.
$$

Where $f_{0}$ and $U_{0}$ are rated voltage and frequency of the micro-grid respectively. $\mathrm{P}_{i}$ and $\mathrm{Q}_{i}$ are the command reference value for the active power and reactive power, $\mathrm{k}_{p}$ and $\mathrm{k}_{q}$ are the droop coefficient of the frequency and voltage respectively.

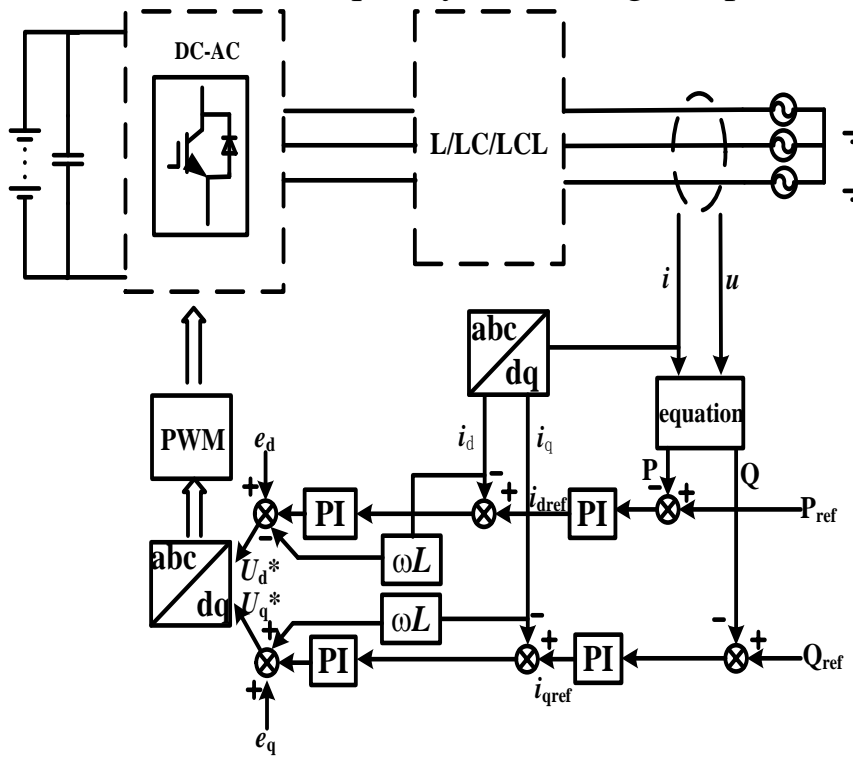

Fig3. PQ control diagram

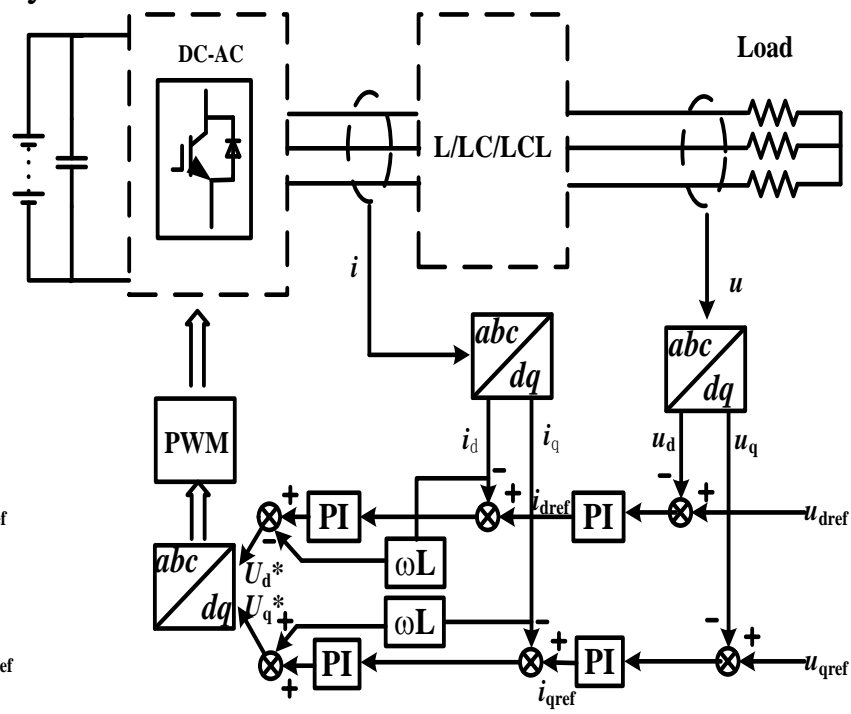

Fig4.V/f control diagram

\section{B. Two-stage PCS}

Figure 5 shows the two-stage PCS topology. This PCS consist of two converters: bidirectional dc-ac converter and bidirectional dc-dc converter. The dc-dc converter is mainly used for boosting or bucking the dc voltage and provide a stable dc voltage. Dc-ac converter work in the state of rectification mode when the battery units release power and convert the ac voltage of the grid to dc voltage. This dc voltage will be regulated by the dc-dc converter and stored in the battery. When the battery release energy, the output dc voltage of the battery units is boosted by dc-dc converter and provide suitable input dc voltage to dc-ac converter. At last output a appropriate ac voltage required by utility grid.

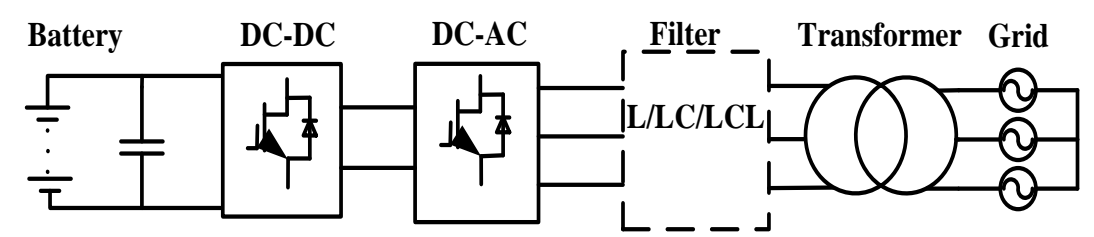

Fig.5 Topology of two-stage power conversion system

In the practical application, bidirectional dc-dc converter is categorized by isolated dc-dc converter and non-isolated converter. The difference between the two kinds of converters is whether there is a high frequency isolation transformer. [3]introduced in detail the traditional non-isolated dc-dc converters such as bidirectional dc-dc converter, bidirectional Boost/Buck converters, bidirectional Cuk converters and bidirectional Sepic converters. They all evolved by basic unidirectional converter. [4]presented a novel converter combined interleaving technology with the non-isolated dc-dc converters so as to lower inductance designing requirements and reduce the voltage and current stress on the switches. The isolated converter mainly include flyback-typed converter, forward-typed converter push-pull-typed converter and bridge-typed converter[5].

The advantages of Two-stage PCS are as follow: the operating voltage rang of the battery unit is relatively higher than the single-stage PCS; the charging current ripple is small and the harmonic component is relatively simple; the second order harmonic component of the charging current in the single-phase or three-phase asymmetric system can be inhibited by dc-dc converter; this structure 
has a high degree flexibility in cells allocation of battery units. However, the drawbacks of this structure consist in the large number of switches which brings more losses and reduce the efficiency of PCS.

For the two-stage PCS, dc-dc converter is used to control charging/discharging current for the battery units, thus a current-loop is adopted to achieve a constant charging/discharging current. While the dc-ac converter is intended to sustain the intermediate dc voltage stability and achieve the goal of the unity power factor operation. A double-loop control scheme consisting of a outer voltage loop and a inner current loop is commonly adopted. The inner current loop is to control the current injected to grid according to the command signal so as to achieving unity power factor operation. While the outer voltage loop is designed to maintain the dc-link voltage and produce command current signal to the inner loop.

Reference[6] presented a control scheme based on repetitive control of harmonic voltage. The harmonic voltage of the reactor could be detected quickly by means of a fast harmonic voltage detection algorithm, and corresponding harmonic voltage is produced to compensate the effect of the grid voltage harmonic by this repetitive control so as to decrease the grid current total harmonic distortion. However this method can not realize zero static error of current tracking. To solve this problem Reference [7] presented a repetitive scheme with voltage feed-forward combined the PI control with the PR control. PI realized the zero static error tracking of the grid-connected current, while PR realized the effective suppression of the selective harmonics, so as to improved the quality of the grid-connected current.

\section{Cascade multilevel PCS}

H-bridge converter is increasingly widely used in practical application. To reduce the batteries nominal voltage, the number of series connected storage cells can be distributed in a number of converter cells making use of the cascaded H-bridge converter. This cascaded H-bridge structure allows direct connection to a medium-voltage grid with less voltage/current harmonics without bring any increase in voltage rating to individual switching devices[8]. Moreover, as the structure of each converter cells are same, that will facilitates the modularization designing and packing. Figure 6 shows the topology of the cascaded multilevel PCS.

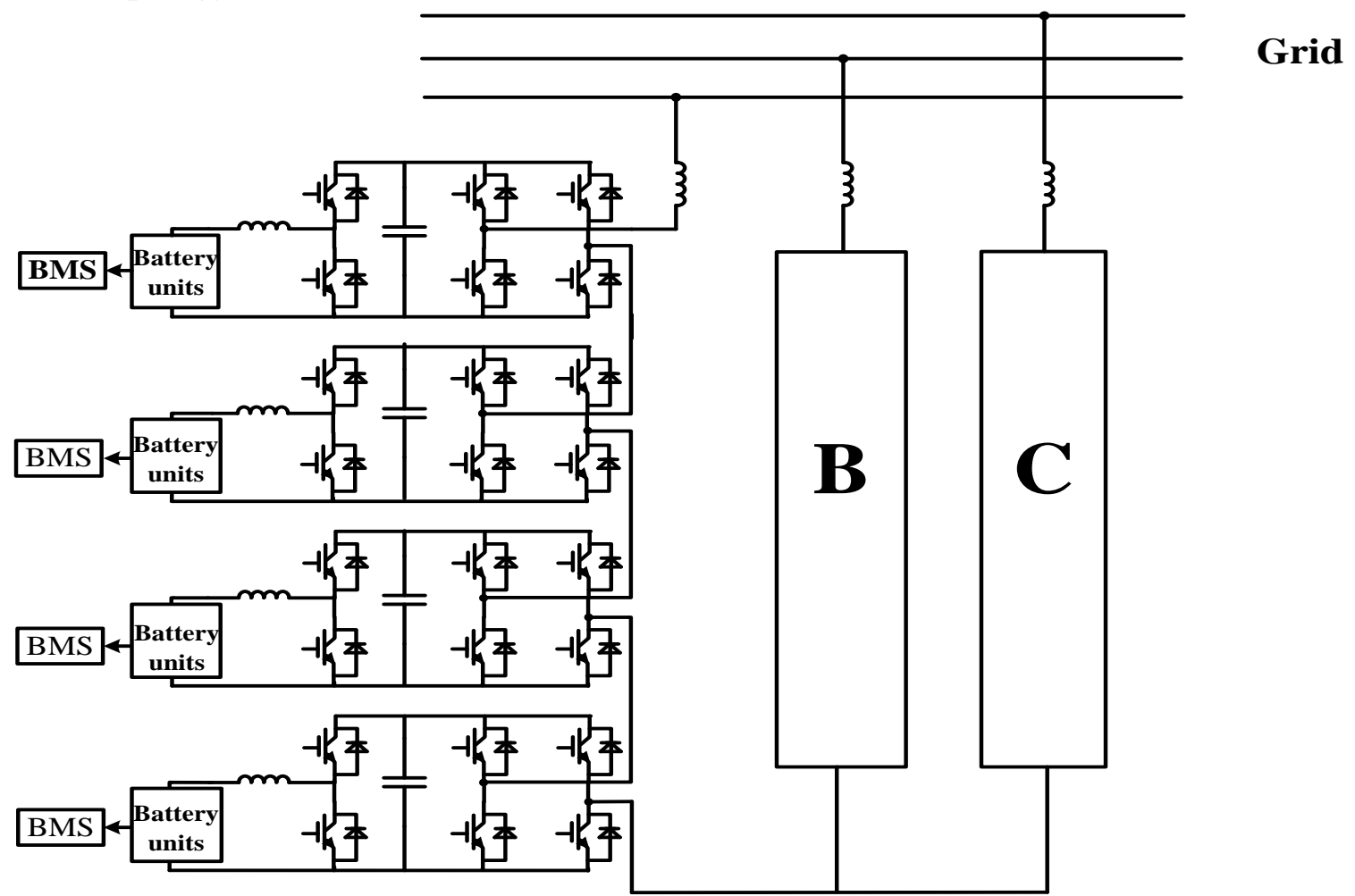

Fig.6 Topology of Cascaded H-bridge Converter

Cascaded H-bridge converter has many advantages. Firstly, multilevel output could upgrade the current quality injected to the grid. Secondly, cascaded structure reduce the voltage in each 
converter cells and bring a reduction to switch losses, and have a equivalent switching frequency under the fundamental switching frequency operating condition. Moreover, it also has a easy and flexible extension capability because of the modular packing of the converter.

In recent years, there are few researches on control strategy of cascaded H-bridge PCS. For this multilevel cascade converter, different control concepts were proposed [9,10,11]. Reference [9] presented a active power control of individual converter cells based on zero-sequence voltage injection. This control based on neutral shift enables the multiple battery units to operate at different power levels while producing a three-phase balanced line-to-line voltage. Reference [10] presented state-of -charge(SOC) balancing control to keep the individual SOC-balancing in all the converter cells. This control mainly consists of two parts: cluster SOC-balancing control between the three clusters and individual SOC-balancing control between the converter cells in each cluster. "cluster" means a set of converter cells connected in series in a phase. Fig 7 shows the control block diagram of the cascaded H-bridge converter.

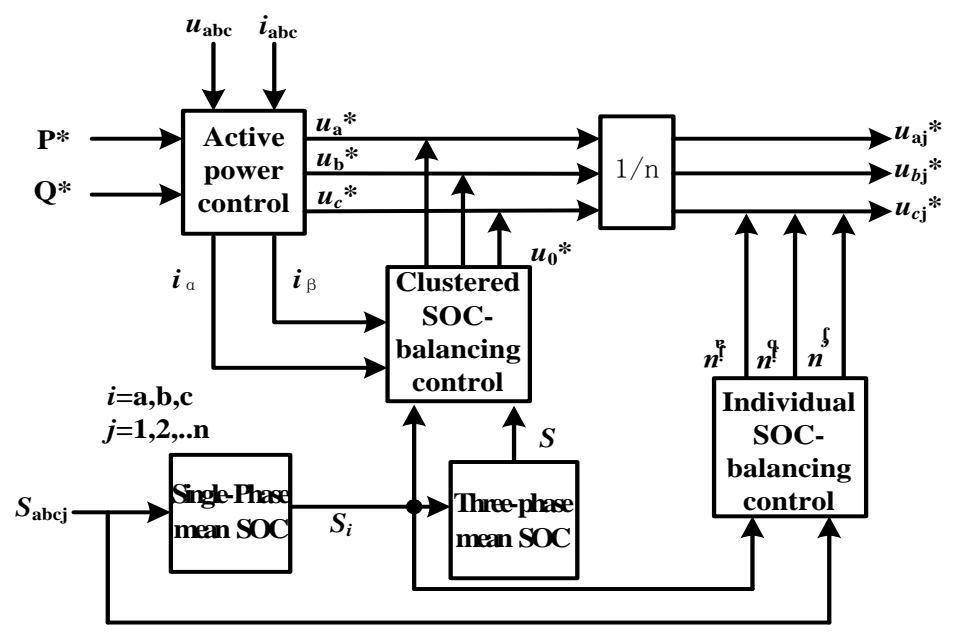

Fig. 7 Control block diagram of cascaded H-bridge PCS

\section{Conclusion}

With the continuous progress of batter technology and power electronics technology, the structure of the PCS will be revised and improved. In the current practical application, single-stage PCS will be commonly and extensively used in the small and medium power application considering the efficiency and cost. While in high power application, the modular cascaded H-bridge PCS is the most suitable choice. The new structure develops towards a direction of less losses, higher reliability, higher efficient cost and higher degree of modularity. Moreover, as the control strategy is becoming more and more mature, PCS could flexibly adopt different control strategies according to different working modes or control targets.

\section{Reference}

[1] R. D. Richardson and G. M. McNerney, Wind energy systems, Proc. IEEE, 1993,81(3):378-389.

[2] Chen Hongbing, Four-leg Power Converter in Power Conversion System(PCS) of Energy Storage and Its Control Strategies, [J]. HeFei University of Technology, 2013.

[3] Xu Haiping, topology of High power bidirectional dc-dc converter and its theoretical analysis and research[D].Beijing, China Electrical Research Institute, 2005.

[4]Wang W.Y, Lu H.H.C, Du W and so on. Multiphase DC-DC converter with high dynamic performance and high efficiency[J]. Power Electronics, IET, 2011, 4(1): 101-110.

[5]Kang Jiuhui, Research of Energy Storage Charge and Discharge Control with Hybrid cascade multilevel converter[D].Gilin: Northeast Dianli University,2013.

[6]Wu Haowei, Duan Shanxu, Xu Zhengxi, A Novel Grid-connected Control Scheme of 
voltage-controlled inverter[J]. Proceedings of the CSEE,2008,28(33):19-24.

[7]Liu Bo, Yang Xu, Kong Fanlin and so on, A Control Strategy of Three-phase Photovoltaic Grid-connected Inverter[J].Transactions of China Electrotechnical Society,2012,27(8):64-70

[8] L. Maharjan, T. Yoshii, S. Inoue, and H. Akagi, A transformerless energy storage system based on a cascade multilevel PWM converter with star configuration, IEEE Trans. Ind,2008,44(5): 1621-1630.

[9]Maharjan L, Yamagishi T, Akagi H. Active-Power Control of Individual Converter Cells for a Battery Energy Storage System Based on a Multilevel Cascade PWM Converter[J]. Owr Lron Ranaon on, 2012,27:1099-1107.

[10]L. Maharjan, S. Inoue, H. Akagi, and J. Asakura, SOC (state-of-charge)-balancing control of a battery energy storage system based on a cascadePWM converter, IEEE Trans. Power Electron, 2009,24(6):1628-1636.

[11]L. Laxman, T. Yamagishi, H. Akagi, and J. Asakura, Fault-tolerant controlfor a battery energy storage system based on a cascade PWM converterwith star configuration IEEE Trans. Power Electron, 2010,25(9):2386-2396. 